\title{
Vulnerability of settling plaice Pleuronectes platessa to predation: effects of developmental stage and alternative prey
}

\author{
H. Wennhage* \\ Department of Marine Ecology, Göteborg University, Kristineberg Marine Research Station, 45034 Fiskebäckskil, Sweden
}

\begin{abstract}
Plaice Pleuronectes platessa L. metamorphose when they change from a pelagic to a benthic habitat during settlement. The effect of developmental stage (i.e. before, during and after metamorphosis) on the vulnerability of reared plaice was tested in laboratory experiments with the epibenthic brown shrimp Crangon crangon as predator. The developmental effect was studied in the presence and absence of the alternative prey Corophium volutator to investigate if the predator's preference for plaice would change with developmental stage. In addition, I investigated the size dependency of shrimp predation on metamorphosing plaice. The vulnerability to predation decreased from the last bilaterally symmetrical stage to the early juvenile stage of plaice, with metamorphosing plaice being intermediate in vulnerability. The decrease was primarily caused by a developmental change in the ability to evade the predator following an encounter. Presence of alternative prey decreased mortality in all developmental stages of plaice, but no interaction was found between the effect of developmental stage and alternative prey to indicate a change in prey preference by the predator. The rapid change in vulnerability to predation during metamorphosis suggests that the developmental stage at settlement is of great importance for the initial survival of plaice recruits. Predation by shrimps on metamorphosing plaice was inversely size-dependent and related to the predator's ability to hold on to the prey once captured.
\end{abstract}

KEY WORDS: Pleuronectes platessa $\cdot$ Crangon crangon $\cdot$ Handling time $\cdot$ Stage-dependent predation · Development · Recruitment - Settlement · Fish · Life history strategy - Alternative prey

Resale or republication not permitted without written consent of the publisher

\section{INTRODUCTION}

Mortality is high during the early life history of most teleost fishes, and predation is considered an important source of this mortality (Houde 1987, Bailey \& Houde 1989). In reviews of predation processes, the relative body size of predator and prey has been identified as a primary factor determining the strength of predator-prey interactions during the larval (Miller et al. 1988, Pepin 1991) and juvenile (Sogard 1997)

*Present address: Marine Sciences Research Center, State University of New York, Stony Brook, New York 11794-5000, USA. E-mail: h.wennhage@kmf.gu.se phases of fishes. Predation rates are dependent on prey size because an increase in size both reduces the number of predator species to which they are vulnerable and the size range of any single predator species able to capture and consume them. As fish larvae develop, their increase in body size will therefore influence their vulnerability to predation. Larval development, however, also involves changes in shape, structure, physiology and behaviour that will affect larval performance (Fuiman \& Higgs 1997). The effect of size and the effect of size as a proxy for development have been studied extensively, but the effect of change in performance caused by the major ontogenetic changes that may occur during metamorphosis has received little attention. 
A large proportion of the benthic marine fish species found in coastal habitats have life-cycles with pelagic larvae which generally undergo a metamorphosis into juveniles at the time of settlement (Breder \& Rosen 1966, Leis 1991). In flatfishes, metamorphosis is profound, includes a $90^{\circ}$ rotation in posture concurrent with the migration of the eye (Fuiman 1997), and a reduction in growth rate in several species (Campana 1984, Markle et al. 1992, Modin et al. 1996, Bertram et al. 1997). The change in performance of flatfish during metamorphosis could therefore be expected to be governed primarily by developmental changes in structure, physiology and behaviour, rather than growth in size, but whether these changes affect flatfish vulnerability to predation is largely unknown. The complexity found during the niche shift of metamorphosing demersal fish has led researchers to describe it as a 'transition phase' rather than as an instantaneous settlement (Kaufman et al. 1992, McCormick \& Makey 1997). The transition phase has been divided into 2 parts: an exploratory period, when recruits search for suitable settlement habitats, and a second period, when recruits complete their metamorphosis and adopt the behaviour of juveniles. Hence, the predator-prey interactions during this phase could be expected to change rapidly over time.

Most models concerning predation success are expressed as a product of the probabilities of encounter, attack and capture (O'Brien 1979, Fuiman \& Magurran 1994). Estimates of encounter rate of a flatfish with an epibenthic predator during settlement are complicated by the fact that settlement is gradual. Plaice Pleuronectes platessa larvae of late bilateral symmetrical stage (Stage $3 b$ according to Ryland 1966) show settlement behaviour in the laboratory but are predominantly pelagic, and the proportion of time on the bottom increases through metamorphosis (Wennhage \& Gibson 1998). Bilaterally symmetrical plaice larvae are occasionally found during benthic sampling (Modin \& Pihl 1996, Wennhage 1999), but habitat segregation between a predominantly pelagic prey and an epibenthic predator could have a major effect on encounter rates even in the limited water depth of a flatfish nursery ground (Witting \& Able 1995).

Observations from the field show that the interannual variability in recruitment of plaice is mainly generated during the pelagic stages and subsequently dampened during the juvenile stage (Zijlstra et al. 1982, Beverton 1995). There is, however, a lack of information on the ability of settlement processes to generate or dampen variability in recruitment. Field studies demonstrate that flatfish suffer from high mortality during and shortly after settlement (van der Veer \& Bergman 1987, Tanaka et al. 1989), and that mortality rates subsequently decrease during the juvenile stage (Beverton \& Iles 1992). Plaice settle on the nursery grounds at a length of 10 to $15 \mathrm{~mm}$, which coincides with the size range at metamorphosis (van der Veer 1986). Brown shrimp Crangon crangon (>30 mm total length [TL]) has been identified as a major predator on newly settled plaice, and stomach content analysis show that plaice consumed consist predominantly of settlement size individuals $\leq 15 \mathrm{~mm}$ TL (van der Veer \& Bergman 1987). Earlier experimental studies of shrimp predation on plaice have focused on sizedependent mortality during the early juvenile stage, when plaice are 16 to $30 \mathrm{~mm}$ in TL. The rapid decrease in mortality risk with increasing size of plaice was attributed to improved escape capabilities of the prey after capture, and it was also concluded that prey profitability decreased with increasing prey size (van der Veer \& Bergman 1987, Gibson et al. 1995). The negatively size-dependent mortality rates and stomach content analysis of predators from the field, in combination with the predator-prey size relationships found in the laboratory, indicate that shrimp predation on plaice would be most intense during and shortly after settlement. Thus, without knowledge of predation processes that occur during settlement the understanding of recruitment regulation in plaice will be incomplete.

Most studies on early-life predation mortality in fish tend to concentrate on the interaction between the predator and a single prey and take no account of the presence of alternative prey. In the wild other prey will be available, presenting the predator with a choice. The brown shrimp is a generalist predator on shallow soft bottoms along the Swedish west coast and the amphipod Corophium volutator is a dominant prey item for large ( $\geq 26 \mathrm{~mm}$ TL) shrimps during April and May, when plaice settle (Pihl \& Rosenberg 1984). Newly settled plaice normally occur in densities ranging from 0.1 to 10 ind. $\mathrm{m}^{-2}$ (Pihl \& van der Veer 1992, Modin \& Pihl 1994), and the overwintering population of C. volutator in densities of 0 to 12000 ind. $\mathrm{m}^{-2}$ (Möller \& Rosenberg 1982). Prey choice of shrimps between plaice and C. volutator is therefore likely to be at least as important as prey choice between plaice of different size or developmental stage.

The present study describes the results of experiments undertaken to determine the effect of plaice developmental stage and alternative prey on plaice vulnerability to shrimp predation during settlement. The behaviour of predator and prey at different stages was compared through observations in small arenas. The observed behavioural differences were used to explain the difference in mortality between developmental stages in a mesocosm experiment. Finally, the lower size limit of shrimps capable of feeding on metamorphosing plaice was determined. Specifically it was 
predicted that: (1) the developmental stage of plaice affects their vulnerability to predation by shrimps and (2) the presence of alternative prey affects the predation rates on plaice and interacts with the effect of developmental stage.

\section{MATERIALS AND METHODS}

Experimental animals. Plaice Pleuronectes platessa L. larvae and juveniles used in experiments were reared at Kristineberg Marine Research Station from artificially fertilised eggs. Fertilisation with eggs and milt from several individuals was performed 10 times over $7 \mathrm{wk}$ to assure that plaice of all developmental stages used would be available during the course of the experiments. Larvae for use in experiments were chosen after a visual examination of their developmental stage, using the following characteristics from Ryland (1966): Stage 3c - the caudal extremity of the notochord bent straight upwards and eyes symmetrical, Stage $4 b / 4 b^{\prime}-$ left eye visible when viewed from the right side, and Stage 5-pupil of the left eye visible when viewed from the ocular side. Mean total lengths of the 3 stages of plaice used in the experiments were the same as for the subsamples used to estimate prey biomass (see Table 1).

Brown shrimps Crangon crangon L. were collected weekly in a shallow plaice nursery ground. Shrimps were checked for damage to their antennae and deprived of food for $2 \mathrm{~d}$, including acclimation time, before use. Shrimp total lengths were measured to the nearest $\mathrm{mm}$ from the tip of the rostrum to the end of the telson after the experiments. Mean total length (SD) of shrimps was 33.4 (1.2), 33.3 (1.3) and 33.6 (1.1) mm (range: 32 to $35 \mathrm{~mm}$ ) for the treatments with larvae, metamorphosing plaice and juveniles, respectively.

The overwintering generation of Corophium volutator (Pallas) collected locally was used as alternative prey. Subsamples of $C$. volutator and the 3 developmental stages of plaice $(n=20)$ were blotted dry and weighed to estimate the wet weight biomass of the different prey items (Table 1). These measurements of prey biomass were used to calculate mean food intake (mg per $12 \mathrm{~h}$ ) and prey profitability $\left(\mathrm{mg} \mathrm{min}^{-1}\right.$ ) for shrimps in the different treatments.

Expt 1: observations of the predation process. The experiment, based on the methods used by Gibson et al. (1995), was done in 2 transparent Perspex tanks (20 $\times 15 \times 6 \mathrm{~cm}$, volume: $1.8 \mathrm{l}$ ) standing on an opaque glass plate. Water temperature in the static system ranged from 11.2 to $14.5^{\circ} \mathrm{C}$. All trials were done in darkness, and infrared light for video recordings was provided by diodes $(880 \mathrm{~nm})$ directed towards a white surface $25 \mathrm{~cm}$ below the glass plate. Two black-and-white television cameras, connected to VHS video recorders, were used to film the arenas from above. Six replicates with Corophium volutator and 6 of each of the 3 developmental stages (3c, 4b and 5) of plaice were staged in random order. One shrimp (32 to $35 \mathrm{~mm} \mathrm{TL}$ ) was allowed to acclimate in the arena for $16 \mathrm{~h}$. Four prey items were then introduced in each tank and the video recording started. After $3 \mathrm{~h}$ the number of plaice or $C$. volutator was made up to 4 again by replacing prey that had been eaten. Videotapes were changed, and the trials were left for another $3 \mathrm{~h}$ before the experiment was terminated.

The behaviour of predators and prey was analysed from the video recordings. An encounter was defined as physical contact between a predator and a prey. A predator was considered as active if it was moving during an encounter irrespective of prey movements. The escape response was divided into horizontal and upward escape into the water column when prey were benthic, pelagic escape after an encounter in the water column, and no response. A prey was regarded as captured when held by the predator for $1 \mathrm{~s}$ or more, and the prey could subsequently escape or be consumed. Handling time was defined as the period between capture and the initiation of predator grooming behaviour when the prey had been consumed, as defined in Gibson et al. (1995). Prey profitability (mg prey ingested $\mathrm{min}^{-1}$ ) of the different prey types was calculated as mean wet weight of the prey types divided by predator handling time for the first prey consumed within a trial. In trials with Corophium volutator as prey, the analysis of behaviour was limited to handling time of the first prey within each trial.

Table 1. Wet weight and total lengths (with $\mathrm{SD} ; \mathrm{n}=20$ ) of subsampled plaice Pleuronectes platessa and amphipods Corophium volutator used in the experiments

\begin{tabular}{|lcccc|}
\hline & \multicolumn{3}{c|}{} & \multicolumn{2}{c|}{ C. volutator } \\
\cline { 2 - 4 } & Larva & Metamorphosing & Juvenile & \\
\hline Developmental stage & $3 \mathrm{c}$ & $4 \mathrm{~b} / 4 \mathrm{~b}^{\prime}$ & 5 & Adults \\
Wet weight (mg) & $6.01(1.13)$ & $7.46(0.96)$ & $9.82(2.00)$ & $8.78(3.58)$ \\
Total length (mm) & $10.6(0.82)$ & $11.5(1.00)$ & $11.8(0.83)$ & $7.65(1.38)$ \\
\hline
\end{tabular}


To compare encounter rates irrespective of the number of prey remaining, an index was constructed, representing encounters prey ${ }^{-1} \mathrm{~h}^{-1}$ :

$$
\text { encounter rate index }=\sum N_{\mathrm{p}}^{-1} t_{\mathrm{s}}^{-1}
$$

where $N_{\mathrm{p}}=$ number of prey present during the encounter, and $t_{\mathrm{s}}=$ search time defined as the time (h) when prey was present during a trial, excluding handling time. Differences in shrimp handling time, capture success in relation to the total number of encounters and encounter rate index of the 3 developmental stages of plaice were tested with 1-way ANOVAs followed by Student-Neuman-Keul's (SNK) post hoc tests $(p<0.05)$. No departures from homoscedasticity were found between treatment means (Cochran's $C$-test: $\mathrm{p}>$ 0.05; Snedecor \& Cochran 1967).

The effect of differences in size between developmental stages was accounted for by using the equation derived for juvenile plaice and shrimp by Gibson et al. (1995):

$$
\arcsin \sqrt{ }(p)=120.89\left(L_{\mathrm{f}} / L_{\mathrm{s}}\right)-17.78
$$

where $p$ is the probability of escape after capture and $L_{\mathrm{f}}$ and $L_{\mathrm{s}}$ are fish and shrimp total lengths, respectively. The plaice used in the present experiments were smaller than those used to establish the relationship, but the prey-predator length ratio (0.32 to 0.35 ) was within the range used.

Expt 2: effect of developmental stage and alternative prey on plaice mortality. The predation experiment was done in black cylindrical tanks $(54 \mathrm{~cm}$ diameter) with flow-through seawater $\left(31 \mathrm{~min}^{-1}\right.$; filtered to $0.8 \mathrm{~mm}$ ) from a nearby nursery ground. Tanks were filled with sediment to a depth of approximately $5 \mathrm{~cm}$ and seawater to a level $30 \mathrm{~cm}$ above the substratum (total volume 80 1). Sediment consisted of sieved $(<0.8 \mathrm{~mm}$ ) beach sand mixed with a small fraction (3\%) of mud to facilitate tube construction by Corophium volutator (Wienberg 1976). Water temperature and salinity ranged from 10.0 to $12.9^{\circ} \mathrm{C}$ and 19.1 to 25.5 PSU, respectively. Illumination was provided by overhead fluorescent lights on a $16 \mathrm{~h}$ light: $8 \mathrm{~h}$ dark cycle approximating the natural daylength at the time of the experiment. In addition, a single light directed towards the ceiling was set on a separate timer to obtain 30 min of dawn and dusk conditions, included in the dark period.

Number of plaice and duration of trials were determined from pilot trials done in smaller tanks (volume $10 \mathrm{l})$ to ensure that differences in mortality between developmental stages of plaice would not be caused by predator satiation. Twenty juvenile plaice, being the largest prey, were added to each of 16 tanks and 1 shrimp predator (32 to $35 \mathrm{~mm} \mathrm{TL;} 34 \mathrm{~mm}$ in mean TL) was placed in 8 of the tanks. These pilot trials showed that a shrimp on average could consume 10.2 (SD = 2.2) juvenile plaice in $12 \mathrm{~h}$.

Predation by shrimps on plaice was tested in an experimental design with developmental stage (3c, 4b/4b' and 5), alternative prey (present, absent) and predator (present, absent) as factors, resulting in 12 treatments each being replicated 12 times. Treatments were randomly allocated between the 12 tanks and over time, with the limitation that not more than 3 replicates of any treatment were to be represented during any one of the 12 trials. Plaice developmental stages consisted of the last bilateral symmetrical larval stage (3c), metamorphosis (4b/4b') and the early juvenile stage (5). All plaice within a trial were chosen from a single batch to ensure that no systematic differences in age since fertilisation was introduced between developmental stages.

One shrimp predator (32 to $35 \mathrm{~mm}$ TL) was introduced in each replicate. Initially, the shrimps were confined to cylindrical cages (diameter $15 \mathrm{~cm}$, height $8.5 \mathrm{~cm}, 1 \mathrm{~mm}$ mesh) with an open bottom pressed down through the sediment to the tank bottom. Twenty Corophium volutator, used as alternative prey, were then distributed evenly at the surface. Predator and alternative prey were allowed to acclimate and bury for $20 \mathrm{~h}$ before 10 plaice were added and the predator cage was removed. Experimental runs were terminated after $12 \mathrm{~h}$ (1.5 h light: $8 \mathrm{~h}$ dark:2.5 h light) by removing the predators with a handnet. The content of the tanks, including the sediment, was then emptied through a $0.8 \mathrm{~mm}$ sieve, and surviving prey items were counted.

The control treatments without predators were used to check the retrieval rate and survival of prey animals. In treatments without alternative prey $100 \%$ of the animals were retrieved alive, and in treatments with alternative prey 99.4 and $99.5 \%$ of plaice and Corophium volutator were found respectively. As the mortality/ loss was negligible in the controls these were not included in subsequent statistical analysis. Food consumption of the predators was calculated from the estimate of mean wet weight of the different food items and the number of prey eaten in each trial. Mortality (number of plaice eaten in $12 \mathrm{~h}$ ) and total biomass of food consumed (mg per $12 \mathrm{~h}$ ) were tested in 2 separate 2-way fixed factor ANOVAs, with alternative prey (present and absent) and plaice developmental stage (larva, metamorphosing and juvenile) as independent variables. Data on total biomass of food consumed had to be log-transformed to obtain homogeneous variances (Cochran's C-test: p > 0.05; Snedecor \& Cochran 1967), whereas the analysis on number of plaice eaten was performed on untransformed data. Treat- 
ment means were compared with a posteriori SNK tests $(\mathrm{p}<0.05)$.

Expt 3: lower size limit of predatory shrimp. The minimum size of shrimp able to capture and consume metamorphosing plaice (Stage $4 \mathrm{~b} / 4 \mathrm{~b}^{\prime}$ ) was investigated in cylindrical tanks (diameter $22 \mathrm{~cm}$, total volume $10 \mathrm{l}$ ) with sediment to a depth of $3 \mathrm{~cm}$. Water temperature in the static system varied from 11.5 to $13.6^{\circ} \mathrm{C}$. Shrimps ranging from 15 to $41 \mathrm{~mm}$ TL were used as predators. One shrimp was introduced to each of 44 tanks $12 \mathrm{~h}$ before the experiment started. Five metamorphosing plaice were released at the surface in each of these tanks and in an additional 4 control replicates. The experiment was terminated after $12 \mathrm{~h}$ by pouring the contents of the tanks through a $0.8 \mathrm{~mm}$ sieve and counting the surviving plaice.

The mechanisms responsible for the lower predator size limit were subsequently investigated with the video set-up and methods of behavioural analysis used in Expt 1. Shrimp just below the size limit for capture of metamorphosing plaice were compared with individuals just above the size limit (4 replicates). The only alteration to the experimental procedure was that 4 shrimps were used as predators in each replicate to increase the number of capture events.

\section{RESULTS}

\section{Expt 1: observations of the predation process}

Predation occurred in all experimental trials. There was no significant difference in encounter rate index (Eq. 1) between predator and prey for the 3 developmental stages of plaice (ANOVA; $F=0.108, \mathrm{df}=2,15$, $\mathrm{p}=0.90$; Fig. 1a). Qualitative observations suggested that plaice became more benthic but less active with developmental stage. There was a significant effect of plaice developmental stage on proportion eaten in relation to the total number of encounters (ANOVA; $F=14.6, \mathrm{df}=2,15, \mathrm{p}<0.001)$. Shrimp had the highest capture success with larvae and the lowest with juveniles, metamorphosing plaice being intermediate in vulnerability (SNK-test at $\mathrm{p}<0.05$; Fig. 1b). Developmental stage also had a significant effect on handling time of the first prey item within a trial (ANOVA; $F=$ 11.9, df $=2,15, \mathrm{p}<0.001$; Fig. 1c). Handling time for juveniles was significantly longer than for larvae and metamorphosing plaice (SNK-test at $\mathrm{p}<0.05$ ).

Shrimps encountered an approximately equal proportion of Stage 3c larvae when they were active $(53 \%)$ versus when they were passive (47\%; Fig. 2a). In the treatments with metamorphosing and juvenile plaice, however, only 10 and $5 \%$ of the encounters occurred when the shrimps were passive. Among the
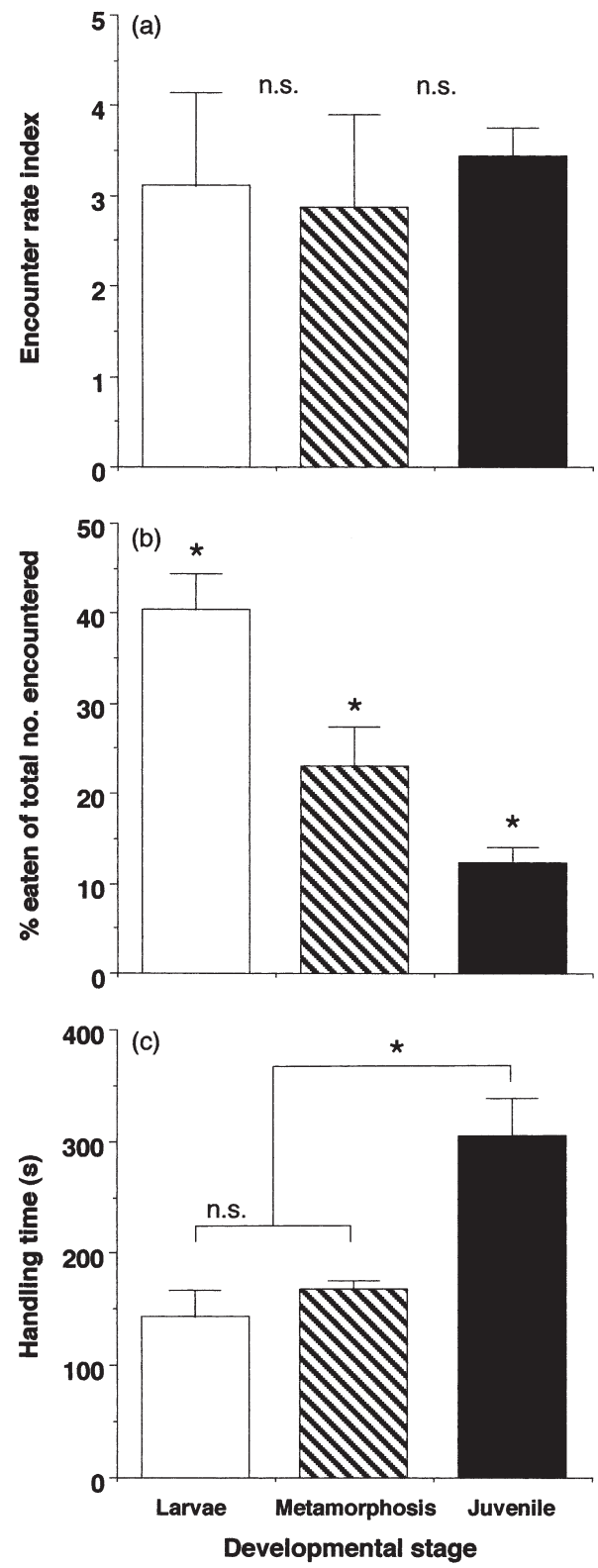

Fig. 1. Comparison of predator (shrimp Crangon crangon) and prey (plaice Pleuronectes platessa) performance in relation to plaice developmental stage (SNK-test at $\star \mathrm{p}<0.05$; ns p $>$ $0.05 ; \mathrm{n}=6$ ). (a) Mean encounter rate between predator and prey adjusted for the number of prey present during an encounter and the time available for a predator to search for prey. (b) Mean proportion of plaice captured and eaten in relation to the total number of encounters between the predator and prey within a trial. (c) Mean predator handling time for the first prey caught in each trial

encounters that resulted in predation, shrimps were passive during 56,25 and $10 \%$ of the occasions with larvae, metamorphosing plaice and juveniles as prey, respectively. Larvae escaped $3.1 \%$ of the time after being captured, and the corresponding proportion for metamorphosing and juvenile plaice was 14.5 and 
$14.2 \%$, respectively (Fig. $2 b$ ). The corresponding sizedependent escape rates calculated from Eq. (2) were $12.2,16.2$ and $17.6 \%$ for the 3 developmental stages. Larvae (Stage 3c) and metamorphosing plaice mainly escaped by swimming up into the water column or remained pelagic after pelagic encounters, whereas juveniles predominantly escaped along the bottom (Fig. 2c). The estimated profitability of the 3 developmental stages of plaice was similar for the predatory shrimp (1.94 to $2.66 \mathrm{mg} \mathrm{min}^{-1}$ ), and the profitability of
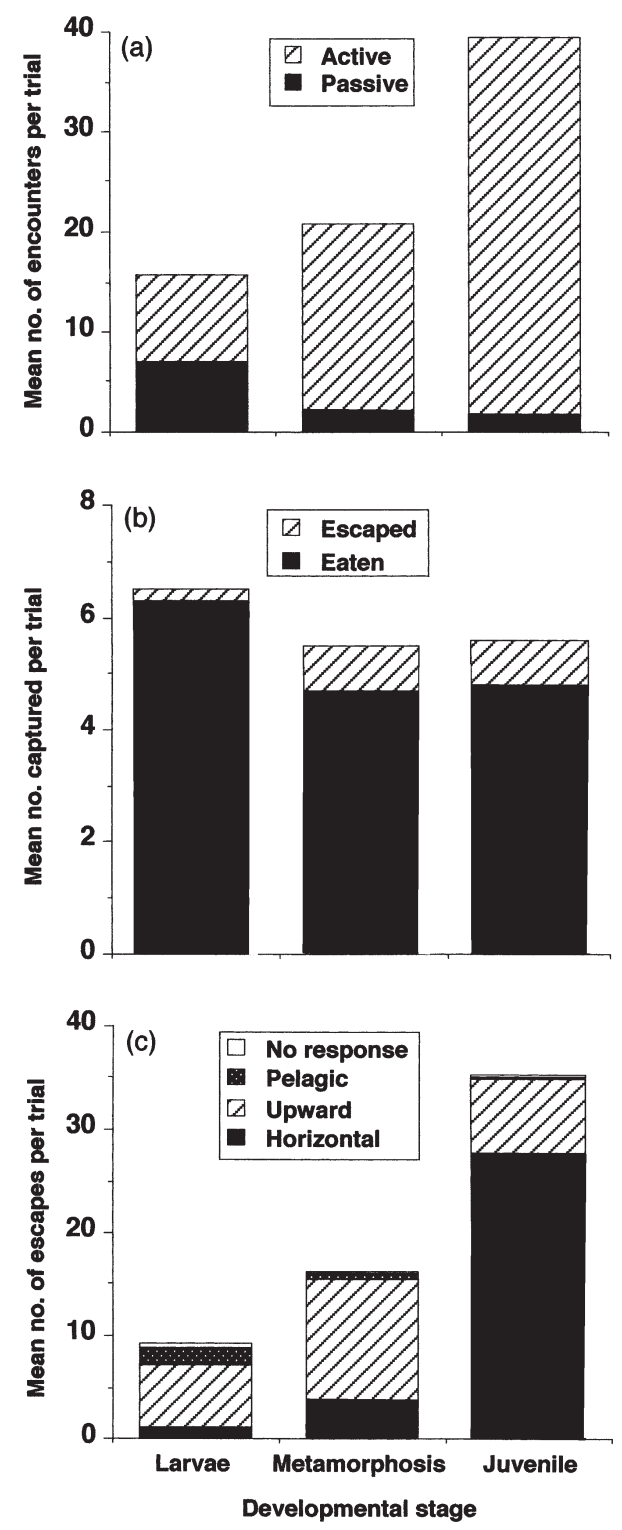

Fig. 2. Observations of predator (shrimp Crangon crangon) 32 to $35 \mathrm{~mm}$ total length and prey (plaice Pleuronectes platessa) behaviour in relation to plaice developmental stage $(n=6)$. (a) Mean number of encounters per trial between predator and prey. (b) Mean number of plaice captured (held for $\geq 1 \mathrm{~s}$ ) per trial. (c) Mean number of prey escapes per trial following an encounter the alternative prey Corophium volutator was estimated at $0.91 \mathrm{mg} \mathrm{min}^{-1}$ (Table 2).

\section{Expt 2: effect of developmental stage and alternative prey on plaice mortality}

There was a significant effect of plaice developmental stage on their vulnerability to predation by shrimp (Table 3). Mortality differed between all 3 developmental stages, with larvae (Stage 3c) having the highest mortality and juveniles (Stage 5) experiencing the lowest mortality (SNK-test at $\mathrm{p}<0.05$; Fig. 3a). Presence of alternative prey reduced predation on plaice significantly, and the reduction in absolute numbers was similar between developmental stages (Fig. 3a), as indicated by the lack of interaction between the effect of developmental stage and alternative prey (Table 3). In the treatments with alternative prey, larvae made up $62 \%$, metamorphosing plaice $45 \%$ and juveniles $27 \%$ of the food items consumed. The major part of this difference in the plaice to alternative prey consumption ratio was caused by differences in predation on plaice, because the consumption of alternative prey was similar between treatments. The mean number of Corophium volutator eaten (with SD) was 4.1 (3.3), 3.75 (2.4) and 5.1 (2.2) for treatments with plaice Stages 3c, 4b/4b' and 5, respectively. The total biomass of food consumed by the predator was significantly higher in treatments with alternative prey compared with treatments where plaice was the only food source (Table 3, Fig. 3b). There was, however, no significant effect of plaice developmental stage on the total biomass of food consumed by the shrimps.

\section{Expt 3: lower size limit of predatory shrimp}

Predation on metamorphosing plaice decreased with predator size, and no predation was observed with shrimps $<17 \mathrm{~mm}$ TL (Fig. 4). In the analysis of the predation process from video recorded trials, shrimps of 15 to $16 \mathrm{~mm}$ TL were compared with those of 17 to $18 \mathrm{~mm}$ TL. The larger shrimps were active during $88 \%$ of the encounters, whereas the smaller size-class encountered an approximately equal number of prey when being active $(46 \%)$ as when they were passive (54\%) (Table 4). The smaller and larger shrimps captured prey during a similar proportion of the encounters, 14 and $11 \%$, respectively. Plaice always escaped after capture when caught by shrimps 15 to $16 \mathrm{~mm}$ TL. The larger shrimps were able to consume their prey $78 \%$ of the time when they had captured a prey, resulting in a mean capture success of $9 \%$ in relation to the total number of encounters. An encounter normally 
Table 2. Profitability and prey/predator length ratio for the different prey types (Pleuronectes platessa, Corophium volutator) used in the experiments with shrimps Crangon crangon 32 to $35 \mathrm{~mm}$ TL as predators

\begin{tabular}{|lcccc|}
\hline & & P. platessa & C. volutator \\
\cline { 2 - 4 } & Larva & Metamorphosing & Juvenile \\
\hline Wet weight (mg) & 6.01 & 7.46 & 9.82 & 11.8 \\
Total length (mm) & 10.6 & 11.6 & 5.07 & 7.65 \\
Handling time of first prey (min) & 2.40 & 2.80 & 33.6 & 9.63 \\
Total length of predators & 33.4 & 33.3 & 1.94 & 33.5 \\
Profitability (mg min (m) $^{-1}$ ) & 2.50 & 2.66 & 0.35 & 0.91 \\
Prey/predator length ratio & 0.32 & 0.35 & & 0.23 \\
\hline
\end{tabular}

Table 3. Two-way fixed factor ANOVA models: The number of plaice Pleuronectes platessa eaten by shrimp Crangon crangon as a function of alternative prey Corophium volutator (present and absent) and plaice developmental stage (larvae, metamorphosis and juvenile), and the total biomass of food consumed by shrimp (log-transformed) as a function of alternative prey (present and absent) and plaice developmental stage (larvae, metamorphosis and juvenile)

\begin{tabular}{|lrrrc|}
\hline Source of variation & SS & df & MS & $F$ \\
\hline Number of plaice eaten & & & & \\
Alternative prey (A) & 100.3 & 1 & 100.347 & $37.8^{* * *}$ \\
Stage (B) & 199.1 & 2 & 99.5 & $37.5^{* * *}$ \\
A $\times$ B & 3.0 & 2 & 1.5 & $0.57(\mathrm{~ns})$ \\
Error & 175.4 & 66 & 2.7 & \\
Biomass consumed & & & & \\
Alternative prey (A) & 0.480 & 1 & 0.480 & $17.69^{* * *}$ \\
Stage (B) & 0.117 & 2 & 0.058 & $2.15(\mathrm{~ns})$ \\
A $\times$ B & 0.076 & 2 & 0.038 & $1.40(\mathrm{~ns})$ \\
Error & 1.790 & 66 & 0.027 & \\
${ }^{* * *} \mathrm{p}<0.001,(\mathrm{~ns}) \mathrm{p}>0.05$ & & & & \\
& & & & \\
\hline
\end{tabular}

resulted in a distinguishable attack response by the predator but the predator never pursued its prey. Shrimps of 17 to $18 \mathrm{~mm}$ TL had a mean handling time of 50 min ( $\mathrm{SD}=6 \mathrm{~min} ; \mathrm{n}=6$ ), and no individual predator consumed more than 1 prey in any one trial.

\section{DISCUSSION}

\section{Effects of developmental stage}

The results from these experimental studies suggest that developmental stage at settlement is an important factor determining plaice survival upon arrival in the nursery grounds as shown by the significant effect of plaice developmental stage on vulnerability to predation by shrimps. Larvae experienced the highest, metamorphosing plaice an intermediate, and juveniles the lowest mortality in the experiments. The intermediate vulnerability of metamorphosing plaice indicates that
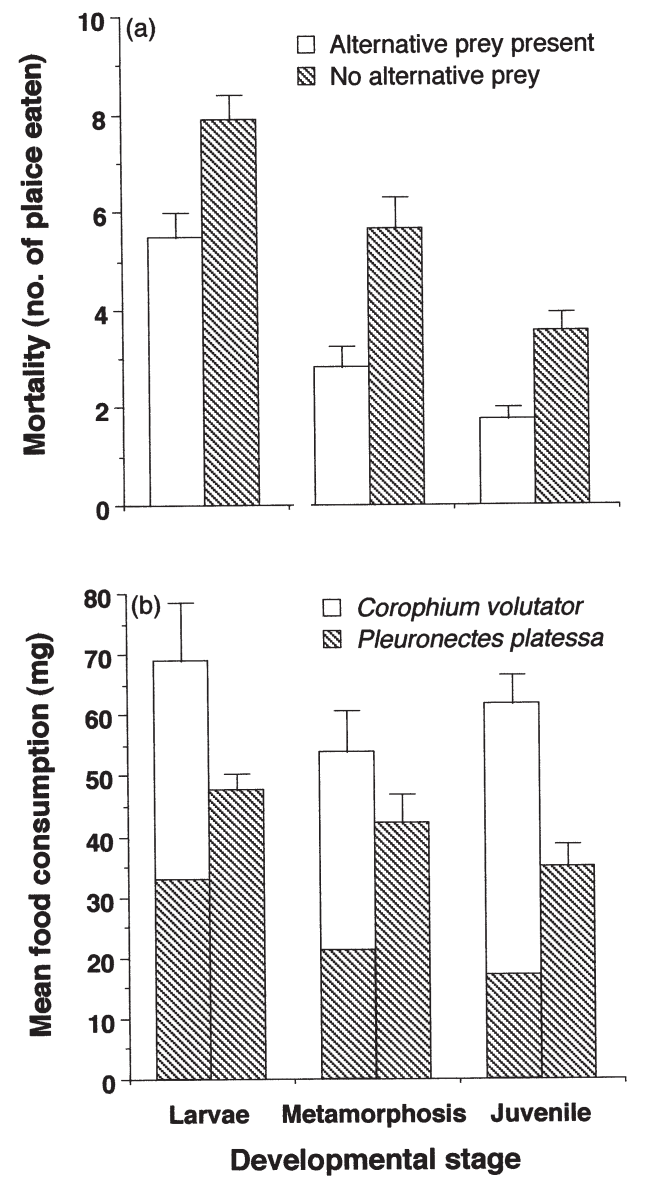

Fig. 3. Predation by 1 shrimp Crangon crangon 32 to $35 \mathrm{~mm}$ TL in relation to plaice Pleuronectes platessa developmental stage and presence of alternative prey (20 Corophium volutator). (a) Mean number of plaice consumed per trial $(+\mathrm{SE})$. (b) Mean total biomass (mg wet weight) of food consumed calculated as mean biomass of prey organisms from Table 1 multiplied by number of prey eaten per trial $(n=12)$

the morphological reorganisation that occurs during metamorphosis does not cause an increase in vulnerability to predation but rather that they have acquired some of the traits which render the juveniles less vulnerable to predation. 


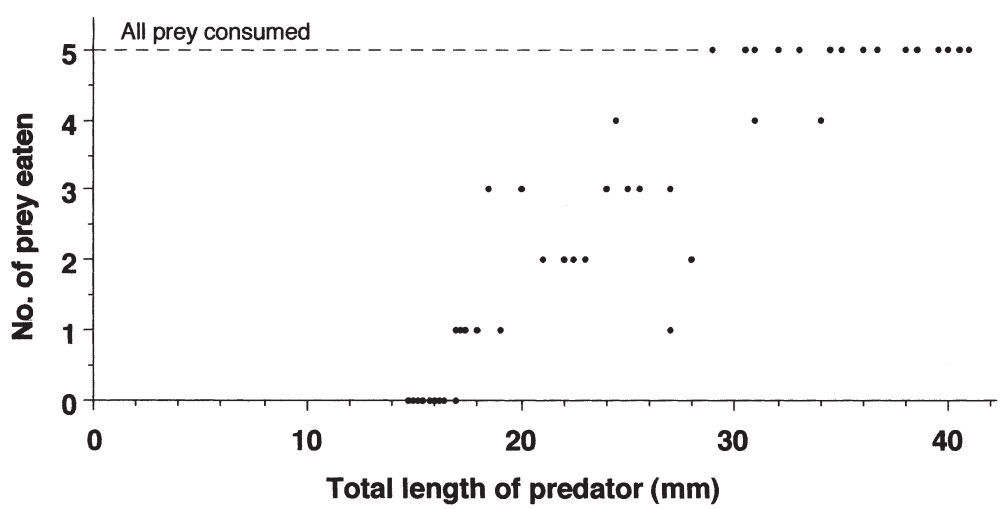

Fig. 4. Number of metamorphosing plaice Pleuronectes platessa eaten during $12 \mathrm{~h}$ in relation to the total length of the shrimp predator (Crangon crangon) present

Table 4. Observations (mean numbers per trial; $\mathrm{n}=4$ ) of encounter rate and capture success of shrimps Crangon crangon (15-16 and 17-18 mm TL) and the escape response of metamorphosing plaice Pleuronectes platessa. The proportion that a behaviour made up of the total number of events within a category is given as a percentage

\begin{tabular}{|lcc|}
\hline & $\begin{array}{c}15-16 \mathrm{~mm} \\
\text { No. }(\%)\end{array}$ & $\begin{array}{c}17-18 \mathrm{~mm} \\
\text { No. }(\%)\end{array}$ \\
\hline Encounter & 19.0 & 32.8 \\
Passive & $10.5(54)$ & $3.5(12)$ \\
Active & $8.5(46)$ & $28.8(88)$ \\
Capture success & 2.8 & 3.5 \\
Eaten & $0(0)$ & $2.8(79)$ \\
Escaped & $2.8(100)$ & $0.8(21)$ \\
Escape response & 18.8 & 29.3 \\
Along bottom & $8.5(40)$ & $14.5(50)$ \\
Upward & $9.3(55)$ & $14.5(48)$ \\
Pelagic & $0.3(1)$ & $0(0)$ \\
No response & $0.8(4)$ & $0.3(1)$ \\
& & \\
\hline
\end{tabular}

Between-developmental-stage differences in the components of the predation cycle were revealed by observations from video recordings. Qualitative observations indicated that plaice became more benthic but less active with developmental stage, resulting in a similar encounter rate per prey and unit time for the developmental stages investigated. The major difference in vulnerability of plaice with development was attributed to an increasing success in evading a predator after an encounter, but the mechanism causing this difference could not be isolated. Differences in predator responsiveness to the 3 developmental stages of plaice were probably of minor importance, as the experiment was performed in darkness and as the developmental stages of plaice were of similar size. Predators did, however, appear to be more successful in capturing plaice of all developmental stages when they were passive compared to when they were active during an encounter. As the activity of plaice seemed to decrease with developmental stage, a predator's reward for a sit and wait strategy would therefore probably decrease with prey developmental stage. The difference in the escape route (horizontal or upward) used by the 3 developmental stages of plaice is another factor that could have influenced the prey's ability to evade a predator. A horizontal alongbottom escape route was used by larvae $14 \%$, metamorphosing plaice $23 \%$ and juveniles $79 \%$ of the time (Fig. 2c). Escape swimming speed of plaice larvae also changes with developmental stage (Bailey \& Batty 1984), and in Pleuronectes americanus escape swimming speed increases linearly with larval length from hatching through metamorphosis (Williams \& Brown 1992). It is therefore unlikely that the small size difference between developmental stages in the present study, being $10 \%$ or less of juvenile TL, would have caused the large difference in vulnerability. The difference in vulnerability could also have been due to changes in the sensory capabilities with development. In plaice, the number of neuromasts and the number of hair cells per neuromast increase during metamorphosis, concurrent with a reorganisation of the neuromasts into trunk canals (Neave 1986, Harvey et al. 1992). The mechanisms behind the difference in the prey's ability to evade a predator after an encounter are likely to be complex and warrant further investigations.

The escape success after capture for larvae (3.1\%) was lower than the escape rate for metamorphosing plaice and juveniles (14.2 and 14.5\%). Juvenile escape rate after capture was close to that predicted from Eq. (2) for juveniles of that size $(17.6 \%)$, which indicates that the present experimental set-up yielded data comparable to that of Gibson et al. (1995). In that study, the escape rate in relation to the total number of encounters was not investigated, but it was concluded that it was the prey's ability to escape once captured that primarily determined the predator's success rate and thereby prey vulnerability. If the predator-prey size relationship for escape success after capture is used (Eq. 2), the effect of difference in size only accounts for 2 to $3 \%$ of the observed difference in vulnerability to predation between the developmental stages. Apart from showing that the changes that occur during metamorphosis have a pronounced effect on predation vulnerability, this result also reflects that growth is reduced during metamorphosis, only generating a very limited difference over which size selection could have an effect. At metamorphosis, size is known to be less variable than age in several flatfish species (Chambers \& Leggett 1987), which indicates 
that size at metamorphosis is important for fitness. In winter flounder Pleuronectes americanus there is, however, no effect of the natural variation in size within stage ( $8 \%$ of TL in metamorphosing fish) on predation risk by Crangon septemspinosa (Bertram \& Leggett 1994). The lack of difference in vulnerability to a benthic predator with size does not, however, imply that size at settlement would be unimportant. Houde (1997) adapted the conceptual ontogenetic niche model of Werner \& Gilliam (1984) to the early life history of fish. According to this model, size at settlement would be a trade off between a size-dependent $M / G$ ratio (mortality per unit growth) in the pelagic versus the benthic habitat. Settlement (metamorphosis) would occur at a size minimising the overall $M / G$. Consequently, size at metamorphosis may not be governed by the vulnerability to benthic predators but could be an effect of the predation risk in the pelagic habitat or the size specific growth in either of the 2 habitats.

The proportion of time spent on the bottom increases with development in plaice (Wennhage \& Gibson 1998), and the water depth could influence the probability of pelagic prey being within the reactive distance of a benthic predator. Witting \& Able (1995) found that newly metamorphosed juveniles of Pleuronectes americanus had the highest mortality when exposed to the predator Crangon septemspinosa. The lower predation on larvae and metamorphosing flounder observed in their study was attributed to habitat segregation between predator and prey, as those stages were pelagic. In the present study habitat segregation did not have a major effect, which indicates a difference in the stagespecific activity and/or the tendency to settle between the 2 flatfish species. Field data indicate that the majority of plaice recruits settle during metamorphosis in tidal (van der Veer 1986) as well as non-tidal (Modin $\&$ Pihl 1994) nursery areas, even though the proportion of premetamorphic plaice in the adjacent water column seem to be higher in non-tidal areas, where water currents are more unpredictable (Wennhage 1999). Estimates of stage distribution at settlement are, however, likely to be biased. A proportionally higher mortality rate of earlier settled stages as shown in this study and the continuing development of recruits from settlement until the time of sampling would bias estimates of the average settlement stage towards later stages. Field studies with high temporal resolution are needed to estimate the stage distribution and mortality rates of settling plaice. The high mortality rate of newly settled plaice in the laboratory indicates that settlement processes may be important for the recruitment dynamics of the species. The settlement period therefore needs to be considered together with the pelagic and benthic juvenile phase in studies of processes that may dampen or generate variability in recruitment.

\section{Effects of alternative prey}

The densities of plaice and Corophium volutator used in the experiment was a compromise between natural densities and densities with a potential to give detectable differences in the analysis. The initial density of plaice in the predation experiment (43.7 ind. $\mathrm{m}^{-2}$ ) was higher than the densities normally found in nursery grounds (0.1 to 3.4 ind. $\mathrm{m}^{-2}$; Pihl \& van der Veer 1992) but has occasionally been recorded at peak settlement. Wennhage \& Pihl (1994) estimated a mean abundance of 17 plaice $\mathrm{m}^{-2}$ in the unvegetated part of a nursery and an average of 74 newly settled plaice $\mathrm{m}^{-2}$ has been recorded (L. Pihl pers. comm.). The initial density of $C$. volutator ( 87 ind. $\mathrm{m}^{-2}$ ) is within the natural density range of the overwintering population, i.e. 0 to 12000 ind. $\mathrm{m}^{-2}$ (Möller \& Rosenberg 1982). The plaice to $C$. volutator abundance ratio used in the experiment is therefore likely to be atypically high but serves the purpose of studying relative differences in vulnerability to predation between developmental stages of plaice.

In the present study, presence of alternative prey reduced the predation on all 3 developmental stages of plaice significantly compared with the treatments without alternative prey. This would be expected to occur even if the predator exhibited no preference between prey types, as the pursuit, capture and consumption of the alternative prey will reduce the amount of time available to feed on plaice. Furthermore, in treatments with Corophium volutator, a predator could feed until satiation as the number of prey and duration of trials had been adjusted for the treatments without alternative prey.

One of the predictions in this study was that there would be an interaction between the effect of developmental stage and alternative prey caused by differences in the predators' preference for the developmental stages relative to the preference for the alternative prey. No interaction was found in the analysis, however, as the reduction in absolute numbers of plaice eaten in the presence of alternative prey was similar for all developmental stages. The interaction term in the 2-way ANOVA model used is, however, only sensitive to non-additive effects of the 2 factors and does not compare the proportional effect that alternative prey had on the different developmental stages. The ratio between the mean number of plaice eaten with or without alternative prey present was calculated to estimate the proportional reduction in plaice mortality within each developmental stage. The presence of alternative prey caused a $37 \%$ reduction in mortality of larvae and a 50 and $51 \%$ reduction for metamorphosing plaice and juveniles, respectively (Fig. 3a). This indicated a decrease in the relative preference for 
plaice with developmental stage. Prey selection by shrimps may, however, not have been expected to change dramatically with developmental stage in the present study as all 3 stages of plaice were found to be more profitable than the alternative prey (Table 2). The results also suggest that the dominance of Corophium volutator in the diet of shrimps in the field is an effect of the relative abundance of $C$. volutator and newly settled plaice rather than predator choice.

\section{Lower size limit of predatory shrimps}

Brown shrimp down to a size of $17 \mathrm{~mm}$ TL were able to capture and consume metamorphosing plaice. Observations of shrimps of 15 to $16 \mathrm{~mm}$ TL showed that the predation cycle was interrupted after capture, as all plaice captured by predators of this size were able to break free and escape. The mechanism is in agreement with the results of Gibson et al. (1995), who found that the size dependency between shrimp and juvenile plaice was caused primarily by the ability of the fish to escape after capture. Even though the mechanism determining the size-dependent predator-prey relationship seemed to be the same for metamorphosing and juvenile plaice, one important difference appeared. In the present experiment, the chance of escape after capture decreased rapidly from 100 to $22 \%$ as predator size increased from $15-16$ to $17-18 \mathrm{~mm}$ TL. In contrast, the predator-prey size relationship for juvenile plaice (Eq. 2) suggests a gradual change in escape success after capture with a change in predator size. The change in escape success in the present study corresponded to a more than 2 -fold difference in fish to shrimp length ratio $\left(L_{\mathrm{f}} / L_{\mathrm{s}}\right)$, as estimated from Eq. (2), but the actual $L_{\mathrm{f}} / L_{\mathrm{s}}$ only changed from 0.66 to 0.74 . Shrimps 17 to $18 \mathrm{~mm}$ TL required a mean handling time of 50 min to consume a metamorphosing plaice. This suggests low profitability given the definition of handling time used in this study. Gibson et al. (1995) provide a plaice wet weight to volume relationship and a shrimp total length to stomach volume relationship. When these relationships are applied to metamorphosing plaice $11.5 \mathrm{~mm}$ TL (wet weight: $7.46 \mathrm{mg}$ ), they show that the fish volume exceeds shrimp stomach volume for shrimps $\leq 25 \mathrm{~mm}$ TL. As satiation was most likely reached before the prey was consumed completely for this size class of shrimps, it would have been more appropriate to measure net energy gain per unit time to represent handling time.

It remains to be seen if shrimps $<30 \mathrm{~mm}$ TL act as predators on plaice in the field. Shrimps 18 to $26 \mathrm{~mm}$ TL have a diet similar to individuals $>26 \mathrm{~mm}$ at the time of plaice settlement, but the size of the dominant food items (Corophium volutator and Nereis spp.) decreases with decreasing shrimp size (Pihl \& Rosen- berg 1984). It therefore seems reasonable to assume that this size range of shrimps would also attempt to attack settling plaice. Van der Veer \& Bergman (1987) did not examine stomachs from shrimps $<30 \mathrm{~mm} \mathrm{TL}$, because their experiments with juvenile plaice 16 to $20 \mathrm{~mm}$ TL had shown that $30 \mathrm{~mm}$ was the lower size limit at which shrimps could capture plaice. The new lower size limit of predatory shrimps found in the present study, by including metamorphosing plaice, could be of importance for estimates of predation pressure in the nursery grounds, because shrimps 17 to $30 \mathrm{~mm}$ TL can comprise more than half of the total shrimp population in a nursery ground at the time of plaice settlement (Wennhage 1999).

In conclusion, this study has shown that a marked reduction in plaice vulnerability to shrimp predation occurs during metamorphosis and that the developmental change in vulnerability is governed by changes during metamorphosis rather than size. Presence of alternative prey reduced the mortality of all 3 developmental stages of plaice investigated, but the expected change in prey preference with plaice developmental stage was not supported in the present study. High vulnerability of settlement stage plaice and the wide size spectrum of shrimps able to consume metamorphosing plaice imply that high mortality occurs during and shortly after settlement. Processes acting during the brief settlement period must therefore be taken into account in studies of recruitment dynamics to avoid bias in estimates of the relative importance of larval supply and postsettlement processes.

Acknowledgements. I am grateful to Robin Gibson, Leif Pihl and 2 anonymous referees for critical comments on this manuscript. Anders Svenson is acknowledged for technical assistance with the experiments and Per-Olav Moksnes for access to his set-up for predation trials. This research was supported by the Swedish Council for Forestry and Agriculture and 'Kungliga \& Hvitfeldska Överskottsfonden'.

\section{LITERATURE CITED}

Bailey KM, Batty RS (1984) Laboratory study of predation by Aurelia aurita on larvae of cod, flounder, plaice and herring: development and vulnerability to capture. Mar Biol 83:287-291

Bailey KM, Houde ED (1989) Predation on eggs and larvae of marine fishes and the recruitment problem. Adv Mar Biol 25:1-83

Bertram DF, Leggett WC (1994) Predation risk during the early life history periods of fishes: separating the effects of size and age. Mar Ecol Prog Ser 109:105-114

Bertram DF, Miller TJ, Leggett WC (1997) Individual variation in growth and development during the early life stages of winter flounder, Pleuronectes americanus. Fish Bull (Wash DC) $95: 1-10$

Beverton RJH (1995) Spatial limitation of population size; the concentration hypothesis. Neth J Sea Res 34:1-6 
Beverton RJH, Iles TC (1992) Mortality rates of 0-group plaice (Pleuronectes platessa L.), dab (Limanda limanda L.) and turbot (Scophthalmus maximus L.) in European waters. II. Comparisons of mortality rates and construction of life table for 0-group plaice. Neth J Sea Res 29:49-59

Breder CM, Rosen DE (1966) Modes of reproduction in fishes. Natural History Press, Garden City, NY

Campana SE (1984) Microstructural growth patterns in the otoliths of larval and juvenile starry flounder, Platichthys stellatus. Can J Zool 62:1507-1512

Chambers RC, Leggett WC (1987) Size and age at metamorphosis in marine fishes: an analysis of laboratory-reared winter flounder (Pseudopleuronectes americanus) with a review of variation in other species. Can J Fish Aquat Sci 44:1936-1947

Fuiman LA (1997) What can flatfish ontogenies tell us about pelagic and benthic lifestyles? J Sea Res 37:257-267

Fuiman LA, Higgs DM (1997) Ontogeny, growth and the recruitment process. In: Chambers RC, Trippel EA (eds) Early life history and recruitment in fish populations. Chapman \& Hall, London, p 225-249

Fuiman LA, Magurran AE (1994) Development of predator defences in fishes. Rev Fish Biol Fish 4:145-183

Gibson RN, Yin MC, Robb L (1995) The behavioural basis of predator-prey size relationships between shrimp (Crangon crangon) and juvenile plaice (Pleuronectes platessa). J Mar Biol Assoc UK 75:337-349

Harvey R, Blaxter JHS, Hoyt RD (1992) Development of superficial and lateral line neuromasts in larvae and juveniles of plaice (Pleuronectes platessa) and sole (Solea solea). J Mar Biol Assoc UK 72:651-668

Houde ED (1987) Fish early life dynamics and recruitment variability. Am Fish Soc Symp 2:17-29

Houde ED (1997) Patterns and consequences of selective processes in teleost early life histories. In: Chambers RC, Trippel EA (eds) Early life history and recruitment in fish populations. Chapman \& Hall, London, p 173-196

Kaufman L, Ebersole J, Beets J, McIvor CC (1992) A key phase in the recruitment dynamics of coral reef fishes: post-settlement transition. Environ Biol Fish 34:109-118

Leis JM (1991) The pelagic stage of reef fishes: the larval biology of coral reef fishes. In: Sale PF (ed) The ecology of fishes on coral reefs. Academic Press, San Diego, p $183-230$

Markle DF, Harris MH, Toole CL (1992) Metamorphosis and an overview of early-life-history stages in Dover sole Microstomus pacificus. Fish Bull (Wash DC) 90:285-301

McCormick MI, Makey LJ (1997) Post-settlement transition in coral reef fishes: overlooked complexity in niche shifts. Mar Ecol Prog Ser 153:247-257

Miller TJ, Crowder LB, Rice JA, Marschall EA (1988) Larval size and recruitment mechanisms in fishes: toward a conceptual framework. Can J Fish Aquat Sci 45:1657-1670

Modin J, Pihl L (1994) Differences in growth and mortality of juvenile plaice, Pleuronectes platessa L., following normal and extremely high settlement. Neth J Sea Res 32: 331-341

Modin J, Pihl L (1996) Small-scale dispersal of juvenile plaice and flounder in relation to predatory shrimp in a shallow Swedish bay. J Fish Biol 49:1070-1085

Modin J, Fagerholm B, Gunnarsson B, Pihl L (1996) Changes in otolith microstructure at metamorphosis of plaice, Pleuronectes platessa L. ICES J Mar Sci 53:745-748

Möller P, Rosenberg R (1982) Production and abundance of the amphipod Corophium volutator on the west coast of Sweden. Neth J Sea Res 16:127-140
Neave DA (1986) The development of lateral line system in plaice (Pleuronectes platessa) and turbot (Scophthalmus maximus). J Mar Biol Assoc UK 66:683-693

O'Brien WJ (1979) The predator-prey interaction of planktivorous fish and zooplankton. Am Sci 67:572-581

Pepin P (1991) Effect of temperature and size on development, mortality and survival rates of the pelagic early life history stages of marine fish. Can J Fish Aquat Sci 48: 503-518

Pihl L, Rosenberg R (1984) Food selection and consumption of the shrimp Crangon crangon in some shallow marine areas in western Sweden. Mar Ecol Prog Ser 15:159-168

Pihl L, van der Veer HW (1992) Importance of exposure and habitat structure for the population density of 0 -group plaice, Pleuronectes platessa L., in coastal nursery areas. Neth J Sea Res 29:145-152

Ryland JS (1966) Observations on the development of larvae of the plaice, Pleuronectes platessa L., in aquaria. J Cons Perm Int Explor Mer 30:177-195

Snedecor GW, Cochran WG (1967) Statistical methods. University of Iowa Press, Ames

Sogard SM (1997) Size-selective mortality in the juvenile stage of teleost fishes: a review. Bull Mar Sci 60: $1129-1157$

Tanaka M, Goto T, Tomiyama M, Sudo H (1989) Immigration, settlement and mortality of flounder (Paralichthys olivaceus) larvae and juveniles in a nursery ground, Shijiki Bay, Japan. Neth J Sea Res 24:57-67

van der Veer HW (1986) Immigration, settlement, and density-dependent mortality of a larval and early post-larval 0-group plaice (Pleuronectes platessa) population in the western Wadden Sea. Mar Ecol Prog Ser 29:223-236

van der Veer HW, Bergman MJN (1987) Predation by crustaceans on a newly settled 0-group plaice (Pleuronectes platessa L.) population in the western Wadden Sea. Mar Ecol Prog Ser 35:203-215

Wennhage H (1999) Recruitment processes in the flatfish Pleuronectes platessa (L.): larval supply, habitat selection and predator-prey interactions at settlement. $\mathrm{PhD}$ thesis, Göteborg University

Wennhage H, Gibson RN (1998) Influence of food supply and a potential predator (Crangon crangon) on settling behaviour of plaice (Pleuronectes platessa). J Sea Res 39: $103-112$

Wennhage H, Pihl L (1994) Substratum selection by juvenile plaice (Pleuronectes platessa L.): impact of benthic microalgae and filamentous macroalgae. Neth J Sea Res $32: 343-351$

Werner EE, Gilliam JF (1984) The ontogenetic niche and species interactions in size-structured populations. Annu Rev Ecol Syst 15:393-425

Wienberg M (1976) Experiments with infrared light on the motion and efficiency of food search of the North Sea shrimp Crangon crangon (Linnaeus, 1758). Ber Dtsch wiss Komm Meeresforsch 24:280-295

Williams PJ, Brown JA (1992) Development changes in the escape response of larval winter flounder Pleuronectes americanus from hatch through metamorphosis. Mar Ecol Prog Ser 88:185-193

Witting DA, Able KW (1995) Predation by sevenspine bay shrimp Crangon septemspinosa on winter flounder Pleuronectes americanus during settlement: laboratory observations. Mar Ecol Prog Ser 123:23-31

Zijlstra JJ, Dapper R, Witte JI (1982) Settlement, growth and mortality of post-larval plaice (Pleuronectes platessa) in the western Wadden Sea. Neth J Sea Res 15: 250-272

Submitted: December 1, 1999; Accepted: April 6, 2000

Proofs received from author(s): August 29, 2000 